\title{
Application Of Numerical Well Testing In Strong Anisotropic Sandstone Gas Field
}

\author{
Yanyan Sun*, Jiwu Fan, Zhenping Xu, and Zhichao Li, Changqing Oilfield, PetroChina, Xi'an, \\ China
}

\begin{abstract}
Sulige gas field in the Ordos Basin, a typical tight sandstone gas field with great heterogeneity, has difficulties in its development because its reservoirs are featured by small-scale effective sandbodies, rapid changes, strong horizontal heterogeneity, and poor connectivity. Analytical well testing widely used in Sulige gas field has limitations. Numerical well testing, which provides a way of tuning a static model with dynamic well testing information, can more accurately estimate reservoir parameters and wellbore effects, and improve the understanding of different types of gas seepage theory.

This study compared the difference between numerical well testing and analytical well testing, and summarized the key points of numerical well testing analysis technology, formed technical ideas of numerical well testing, proposed an interpretation workflow on the typical numerical well testing, and estimated the distribution of the main parameters, such as effective permeability reservoir, fracture halflength, and fracture conductivity, and so on. The interpretation results from various vertical and horizontal wells can deepen the understanding of reservoir and provide valuable technical support for stable gas production.
\end{abstract}

\section{Introduction}

Sulige gas field in the Ordos Basin, a typical tight sandstone gas field with great heterogeneity, has difficulties in its development because its reservoirs are featured by small-scale effective sand bodies, rapid changes, strong plane heterogeneity, and poor connectivity. It plays a crucial role on stabilizing gas production. Well testing can deepen the understanding of reservoir and reduce the uncertainty of estimates.

Currently, analytical well testing widely applied in Sulige gas field has limitations, mainly manifested in three aspects: (1) analytical well testing of reservoir heterogeneity is simplified to the radial composite or linear composite, which is difficult to effectively depict gas field in a complex geological condition and the characteristic of the strong heterogeneity of the reservoir; (2) Analytical well testing is derived by solving a second order partial deferential diffusivity equation. Uncertainty is resulted from the inverse nature of the problem. In general, ideal assumptions are made in order to solve a mathematical model. This results in the limit of its practical application. Analytical solution usually can be derived when a mathematical model is ideal. Non-ideal case (real case) is analysed using solutions derived from ideal model. Engineers use analytical model and solutions (type curves) for well test analysis. The final results are verified by matching analytical solution with measured pressure data. Assumptions made are ignored while perusing "perfect match" during the analysis. Results derived by such an approach are misleading. Well testing-a very useful engineering dynamic measurement itself is flawed due to this practice (Zheng 2006).

Numerical well testing has significant advantages over analytical well testing that assume constant reservoir and fluid properties. By contrast, numerical well testing can handle multiphase flow and stress-

Copyright $(C$ the author(s). This work is licensed under a Creative Commons Attribution 4.0 International License. 
dependant reservoir properties, and relative permeability functions to handle complex problems (Deng et al. 2011). Thus, numerical well testing can more accurately estimate reservoir properties and wellbore effects, and provide valuable technical support for stable gas production.

\section{The Difference between Numerical Well Testing and Analytical Well Testing}

The difference between numerical well testing and analytical well testing is that fluid seepage equation in the porous media are solved by different methods. Seepage equation of analytical well testing is solved by means of analytic expression. However, for numerical well testing, seepage equation is solved by numerical methods and various parameters are calculated in each grid node. Therefore, numerical well testing can be more widely adapted to detailed requirements of actual field applications.

In other words, numerical well testing can overcome almost all the actual problems in analytical well testing, including different permeability, porosity, formation thickness, and fluid saturation at an arbitrary point of the formation, the influence of the reservoir rock stress, the special problems of unconventional reservoirs and multiple well productions, and the effect of interference and irregular internal and external boundary problems, et al.

\section{Numerical Well Testing Technical ideas}

Interpretation of numerical well testing is a technology based on unstructured mesh technology on the complex seepage area. It applies numerical discrete methods to solve the fluid seepage equation, and then determines reservoir parameters, reservoir limits, and wellbore effects (skin and storage) by fitting the measured bottom-hole-pressure and production (Li 2000; Zhuang 2004; Liu 2008).

Figure 1 illustrates the key steps of a numerical well test. First, reservoir numerical model is established by referring the effective thickness, porosity and permeability of geological information. Then, the initial value of the fitting parameters is got by analytic method for numerical well testing interpretation model. The fitting parameters and reservoir numerical parameters are adjusted by validation of production dynamic data to establish numerical well testing model.

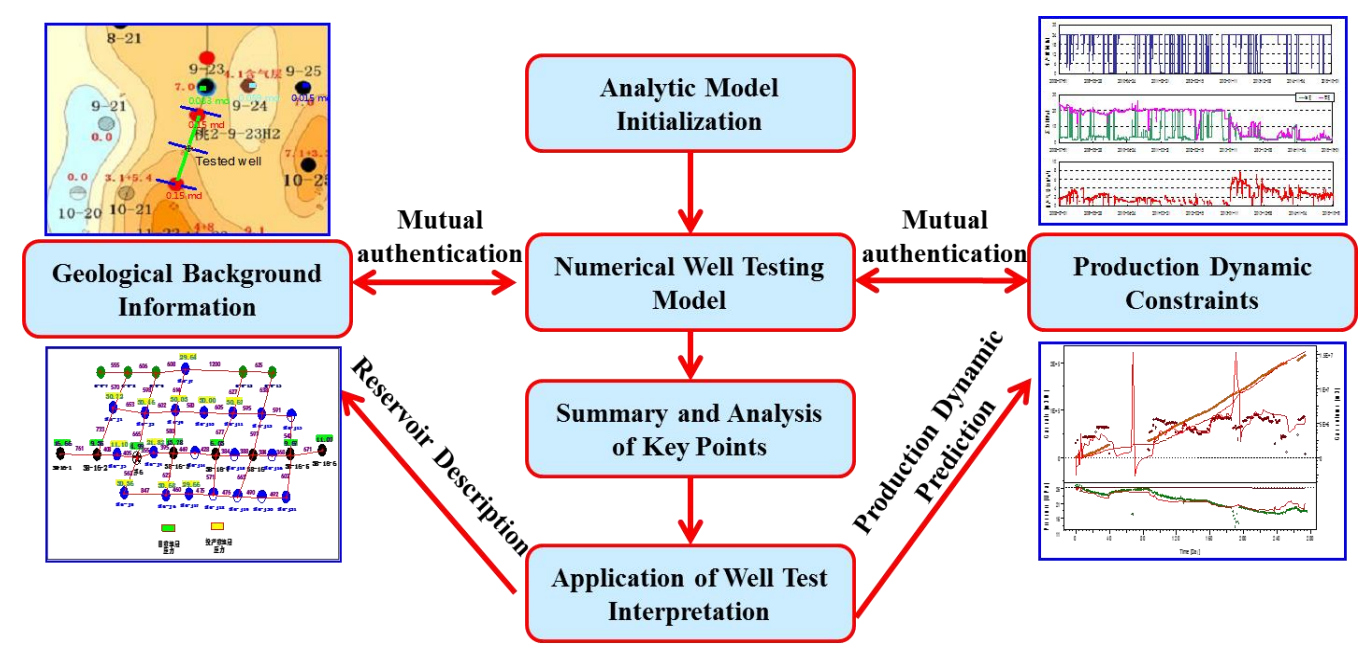

Figure 1-Numerical well testing technology.

Establishing the numerical well testing model not only can accurately characterize heterogeneity of the reservoir, including reservoir thickness, porosity, permeability, boundaries, skin factor, and wellbore storage, but also visually display pressure distribution dynamically.

\section{Key Technical Points of Numerical Well Testing}

Feature recognition of different types of well testing models is the key. Sulige gas field is a typical tight gas reservoir. It needs horizontal drilling and hydraulic fracturing to improve well performance. Thus, it is critical to establish typical curves of unsteady well test based on theoretical study on fractured vertical 
wells and horizontal wells (Wang et al. 2013; Qi et al. 2007; Yang et al. 2010; Wu et al. 2010), as shown in Figure 2 and 3.

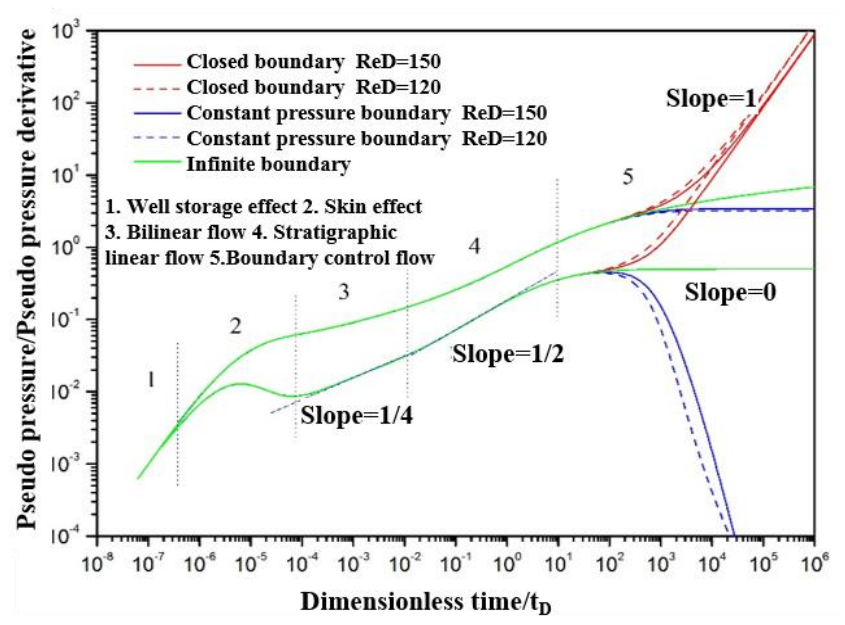

Figure 2-Typical curves of fractured vertical well.

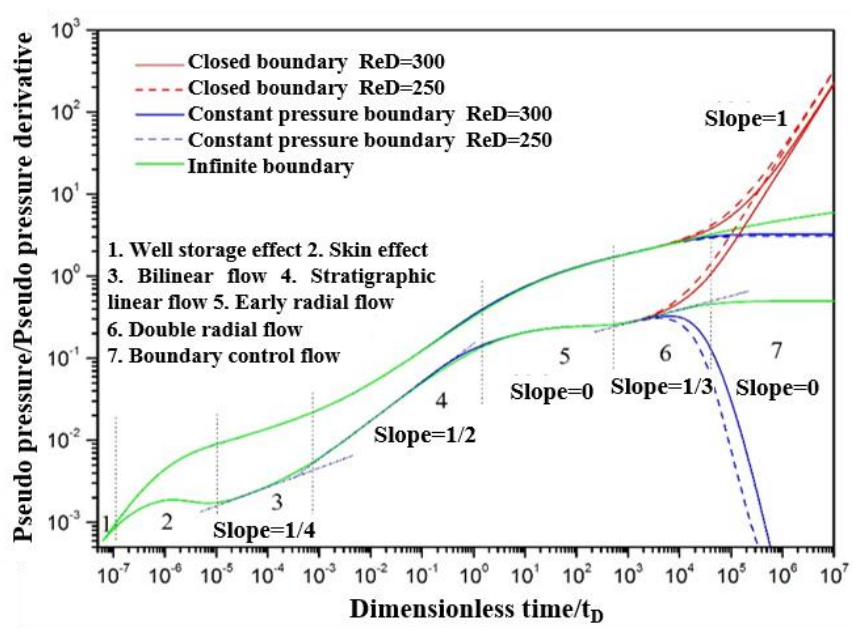

Figure 3-Typical curves of fractured horizontal well.

Permeability heterogeneity has strong effect on the shape of pressure drop curve and pressure derivative curve at the end of the effect of wellbore storage and skin, as shown in Figure 4 and 5. 


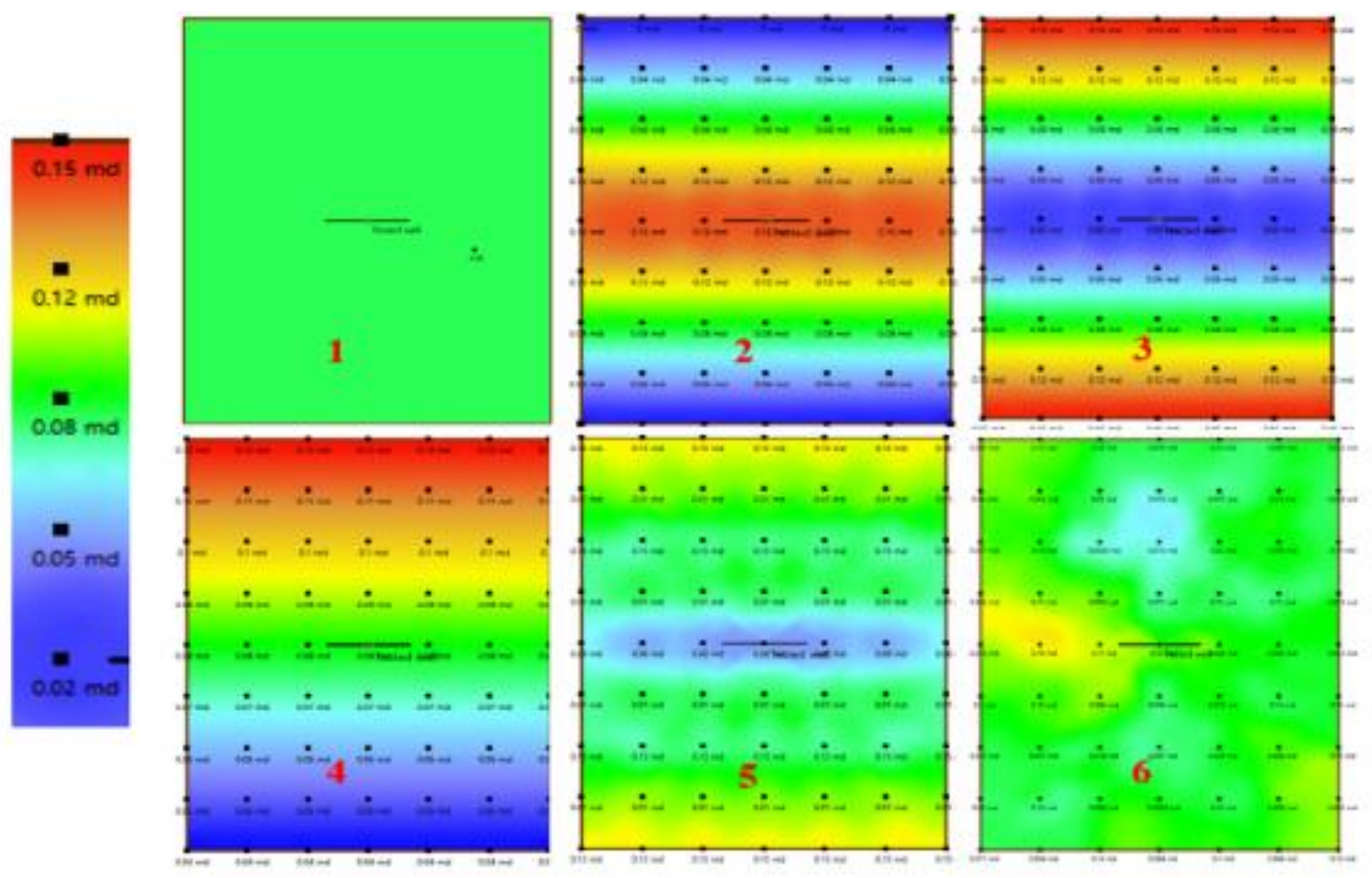

Figure 4-Reservoir permeability distribution.

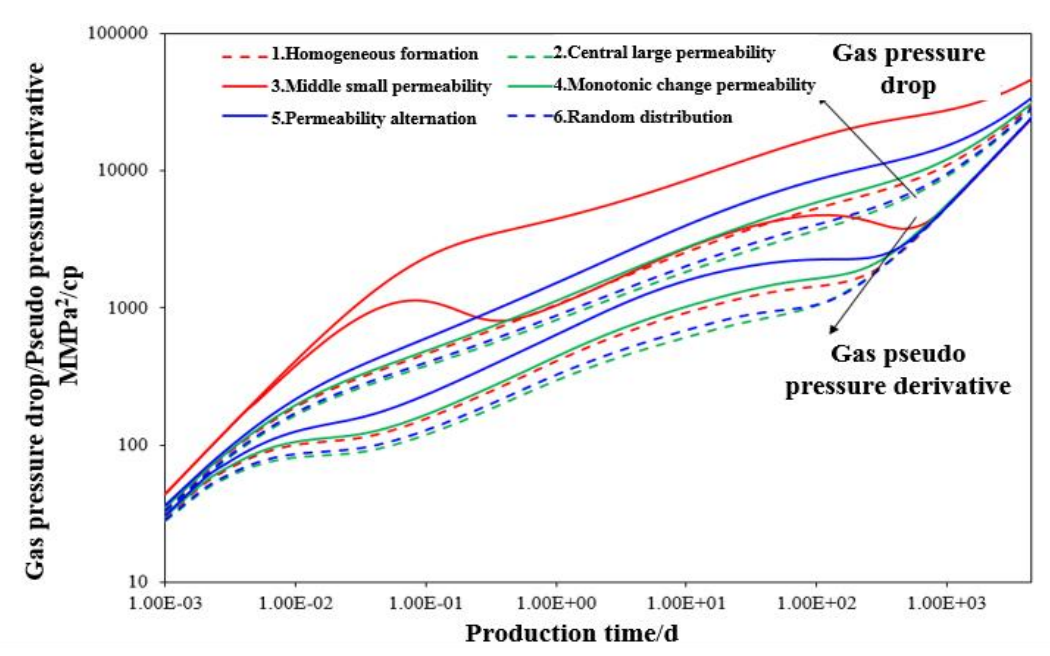

Figure 5-Influence of heterogeneity of permeability on well test curve.

\section{Typical Wells Numerical Well Test Analysis Workflow}

Take SuA-B-CH2 Well as an example. First, we obtained the average reservoir parameters with analytical well testing technique. Interpretation results are shown in Table 1 and Figure 6. Then, we drew the effective sandbodies isopach map (Figure 7). 
Table 1-Analytical well test interpretation results of SuA-B-CH2 well.

\begin{tabular}{c|c}
\hline Parameters & Value \\
\hline Well model & 5 stage fractured horizontal well \\
Reservoir model & Homogeneous reservoir + Infinite boundary \\
$\mathrm{C}\left(\mathrm{cm}^{3} / \mathrm{MPa}\right)$ & 5.39 \\
$\mathrm{~S}$ & -7.11 \\
$\mathrm{Kh}(\mathrm{md} . \mathrm{m})$ & 3.8 \\
$\mathrm{~K}(\mathrm{md})$ & 0.38 \\
$\mathrm{Pi}(\mathrm{MPa})$ & 23.25 \\
$\mathrm{H}_{\mathrm{w}}(\mathrm{m})$ & 331 \\
$\mathrm{X}_{\mathrm{f}}(\mathrm{m})$ & 30.5 \\
$\mathrm{~F}_{\mathrm{C}}(\mathrm{md} . \mathrm{m})$ & 274 \\
\hline
\end{tabular}

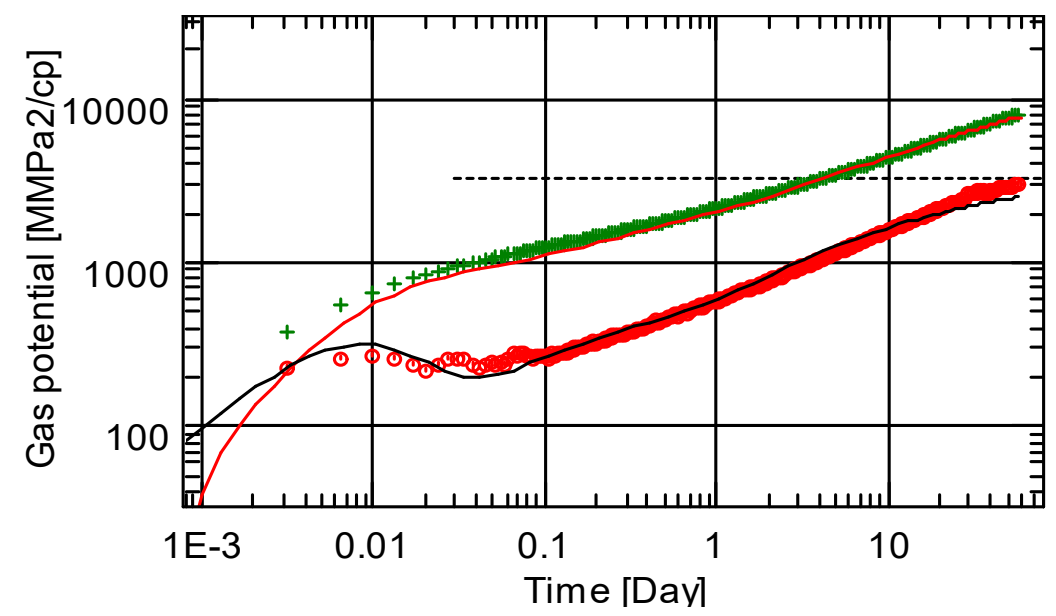

Figure 6-Log-log curves of analytical well test of SuA-B-CH2 well.

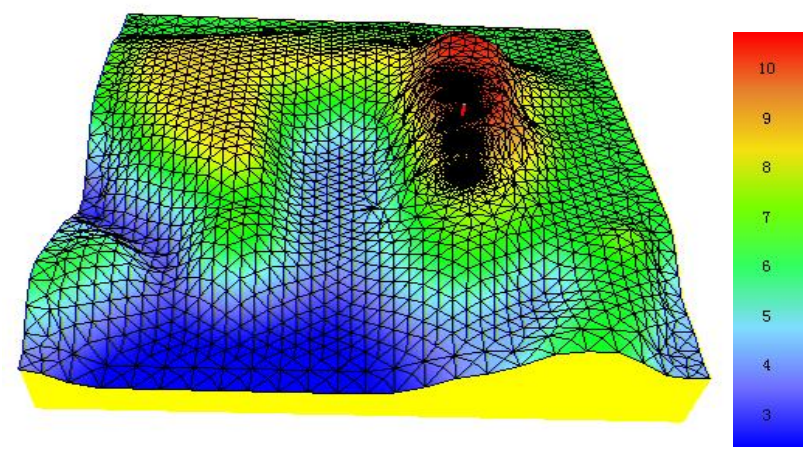

Figure 7-Distribution of effective thickness around SuA-B-CH2 well.

Next, porosity logging data from adjacent wells was used to determine the porosity distribution around SuA-B-CH2 well which is shown in Table 2 and Figure 8. 
Table 2-Porosity statistics of SuA-B-CH2 adjacent wells.

\begin{tabular}{cccc}
\hline Well Name & Porosity $(\%)$ & Well Name & Porosity (\%) \\
\hline SUA-B-13a & 7.2 & SUA-D-9 & 6.6 \\
SUA-C-9 & 6.9 & SUA-D-10 & 9.0 \\
SUA-C-10 & 9.5 & SUA-D-10H1 & 8.4 \\
SUA-C-12 & 9.3 & SUA-D-11 & 9.3 \\
SUA-C-13 & 7.1 & SUA-D-12 & 10.8 \\
SUA-D-13 & 10.9 & & \\
\hline
\end{tabular}

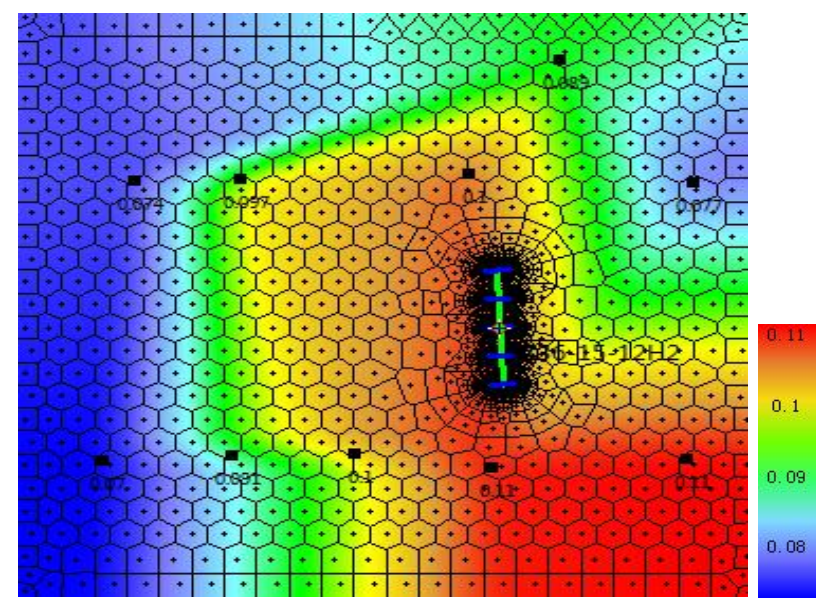

Figure 8-Porosity distribution of SuA-B-CH2 wells.

Based on the analytical solution and geological information constraints, permeability distribution of formation was obtained by fitting the well test data (Figure 9).

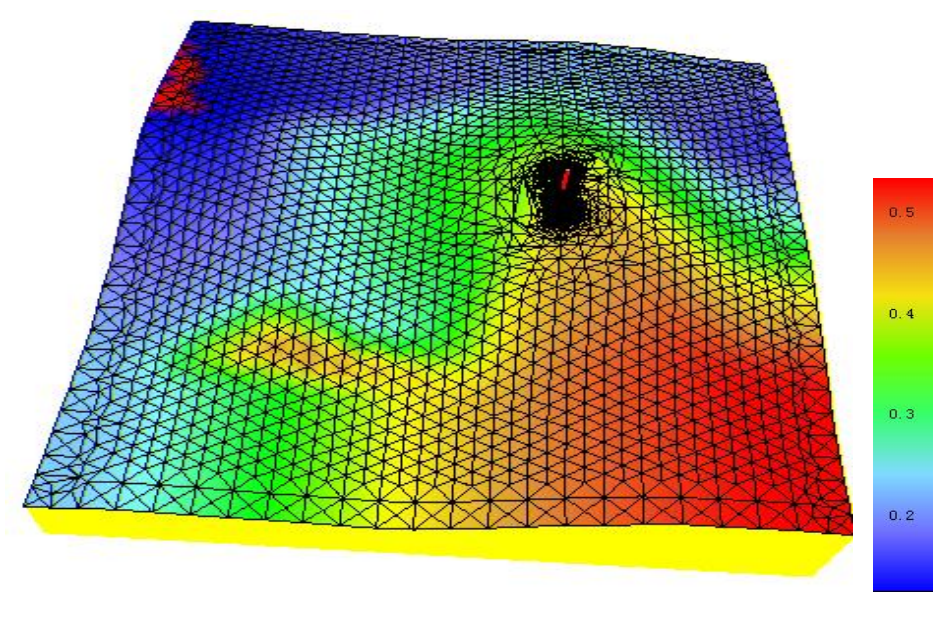

Figure 9-Numerical model of permeability distribution of SuA-B-CH2 well.

Interpretation and fitting results by numerical well test are shown in Table $\mathbf{3}$ and Figure 10, respectively. 
Table 3-Numerical well test interpretation results of SuA-B-CH2 well.

\begin{tabular}{c|c}
\hline Parameters & Value \\
\hline Well model & Numerical model \\
$\mathrm{C}\left(\mathrm{cm}^{3} / \mathrm{MPa}\right)$ & 4.39 \\
$\mathrm{~S}$ & 0.11 \\
$\mathrm{~K}(\mathrm{md})$ & 0.511 \\
$\mathrm{P}_{\mathrm{i}}(\mathrm{MPa})$ & 24.5 \\
$\mathrm{H}_{\mathrm{w}}(\mathrm{m})$ & 331 \\
$\mathrm{X}_{\mathrm{f}}(\mathrm{m})$ & 30.5 \\
\hline
\end{tabular}

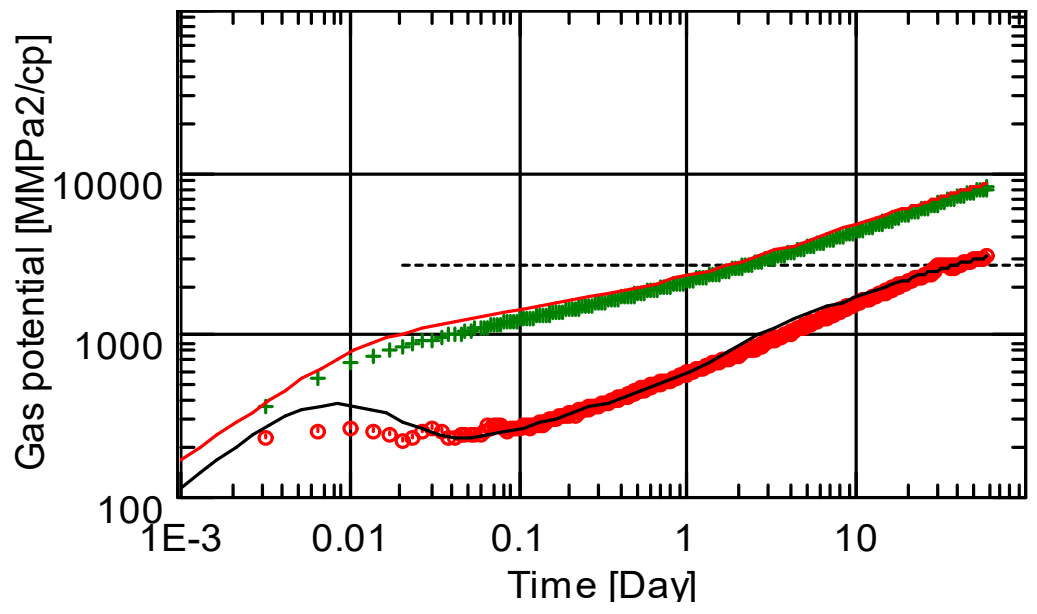

Figure 10-Log-log curves of numerical well test of SuA-B-CH2 well.

\section{The Results of Numerical Well Test Interpretation}

Interpretation Results of Statistics Vertical Numerical Well Testing. Statistics of parameters estimates from 19 vertical wells are shown in Figure 11 through 13. Effective permeability of reservoir is 0.03-0.74 md, with a mean of $0.22 \mathrm{md}$. Fracture half-length is between $11.6 \mathrm{~m}$ and $228.4 \mathrm{~m}$, with a mean of $71.1 \mathrm{~m}$. Fracture conductivity is from 101 to $301 \mathrm{md} \cdot \mathrm{m}$, mean is $167 \mathrm{md} \cdot \mathrm{m}$.

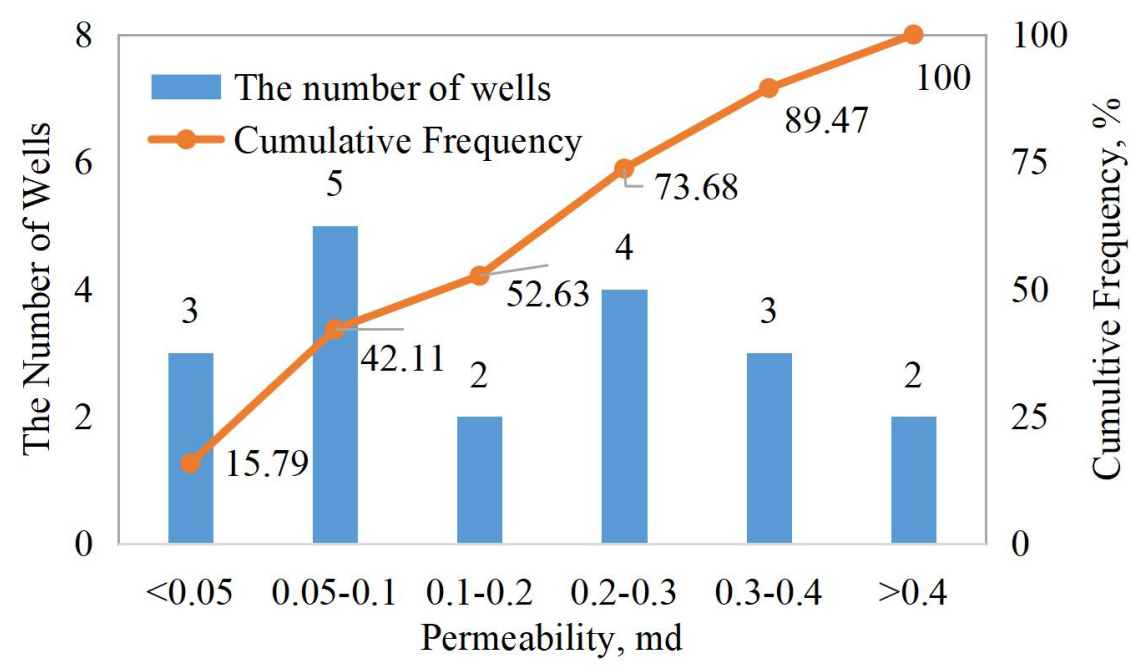

Figure 11-Cumulative frequency distribution of vertical wells permeability. 


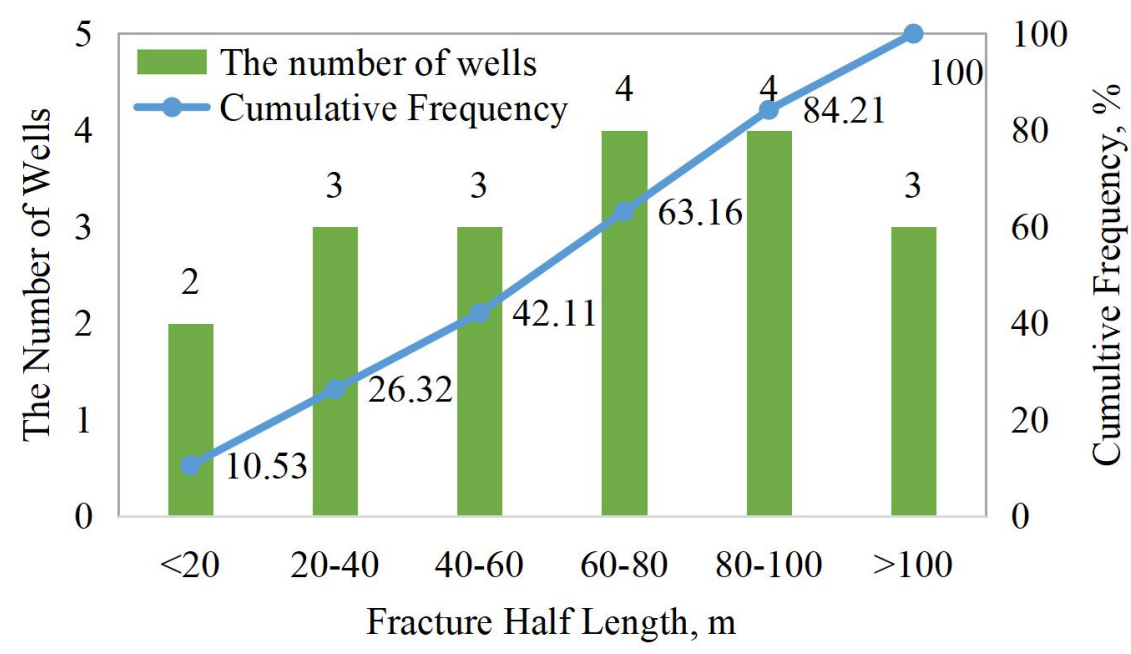

Figure 12-Cumulative frequency distribution of fracture half-length of vertical well.

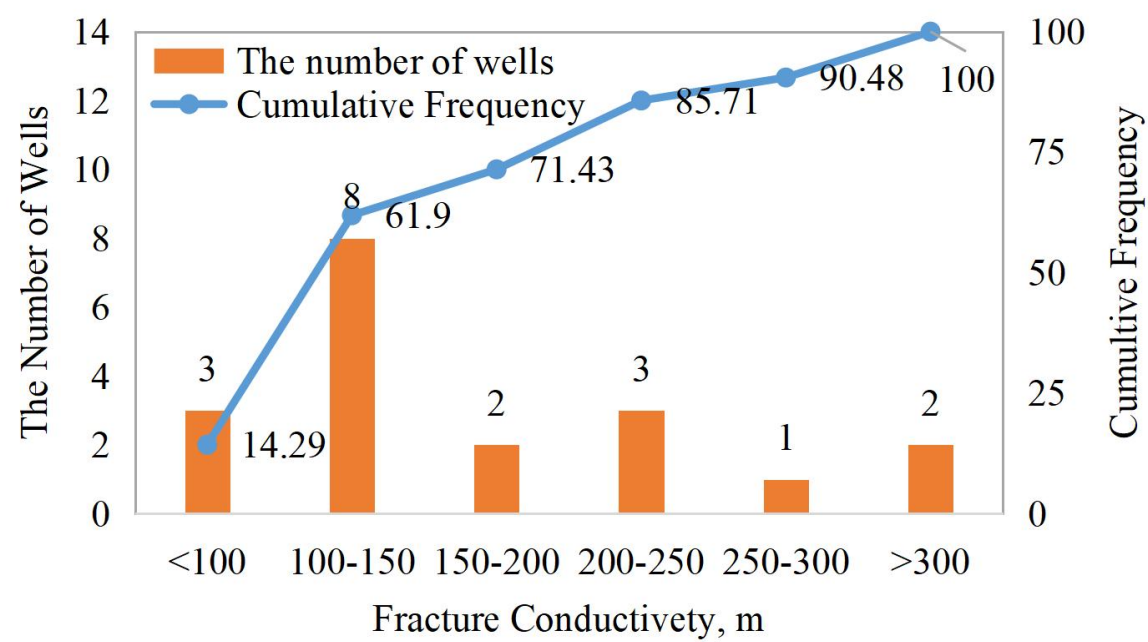

Figure 13-Cumulative frequency distribution of fracture conductivity of vertical wells.

The Horizontal Well Numerical Well Test Interpretation Results of Statistics. Statistics of parameters estimates from 18 horizontal wells are shown in Figure 14 through 16. Effective permeability reservoir is $0.02-0.94 \mathrm{md}$, with a mean of $0.295 \mathrm{md}$. Fracture half-length ranges from 22 to $197 \mathrm{~m}$, with a mean of $65.8 \mathrm{~m}$. Fracture diverting capacity is $26.5-498 \mathrm{md}$, with a mean of $179 \mathrm{md}$.

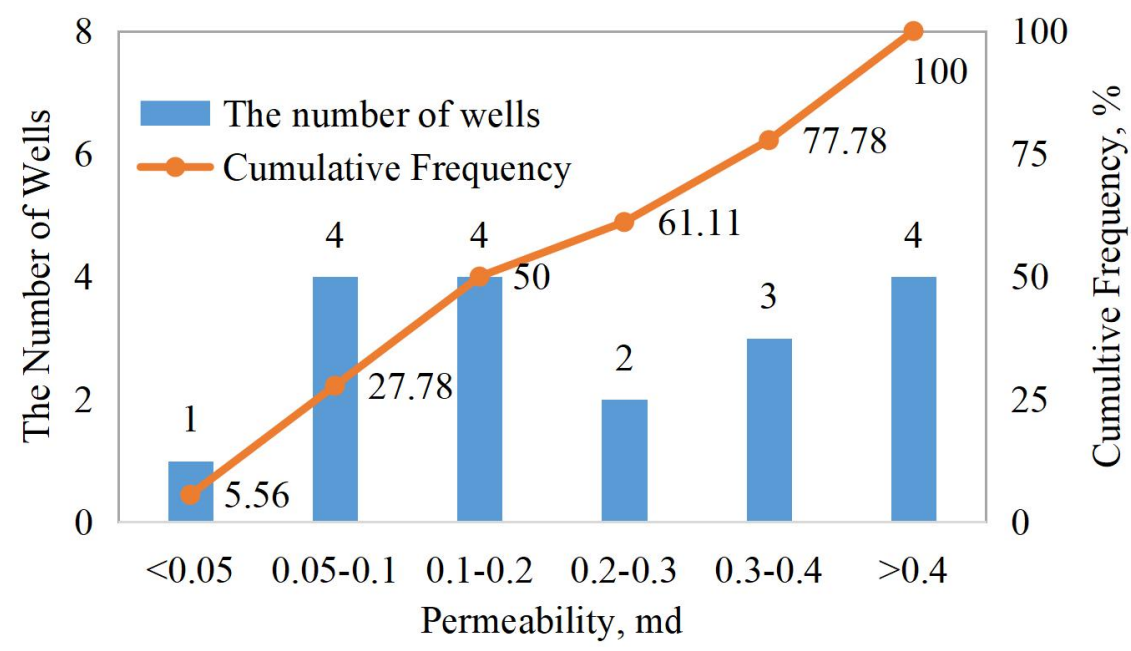

Figure 14-Cumulative frequency distribution of horizontal wells permeability. 


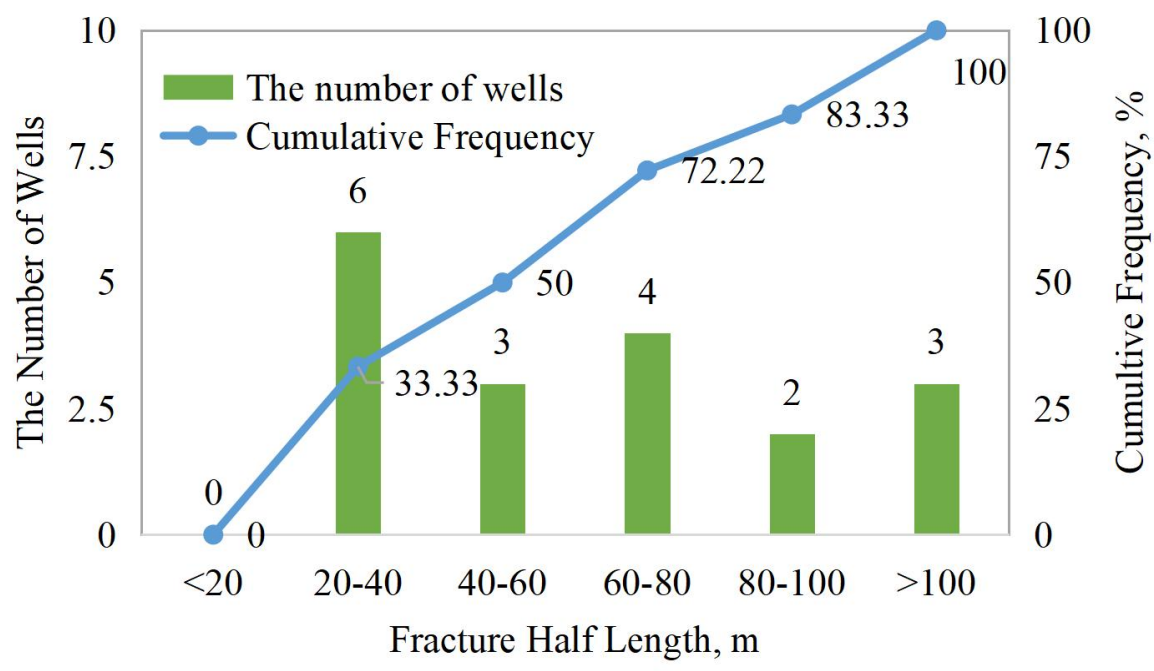

Figure 15-Cumulative frequency distribution of horizontal well fracture half length.

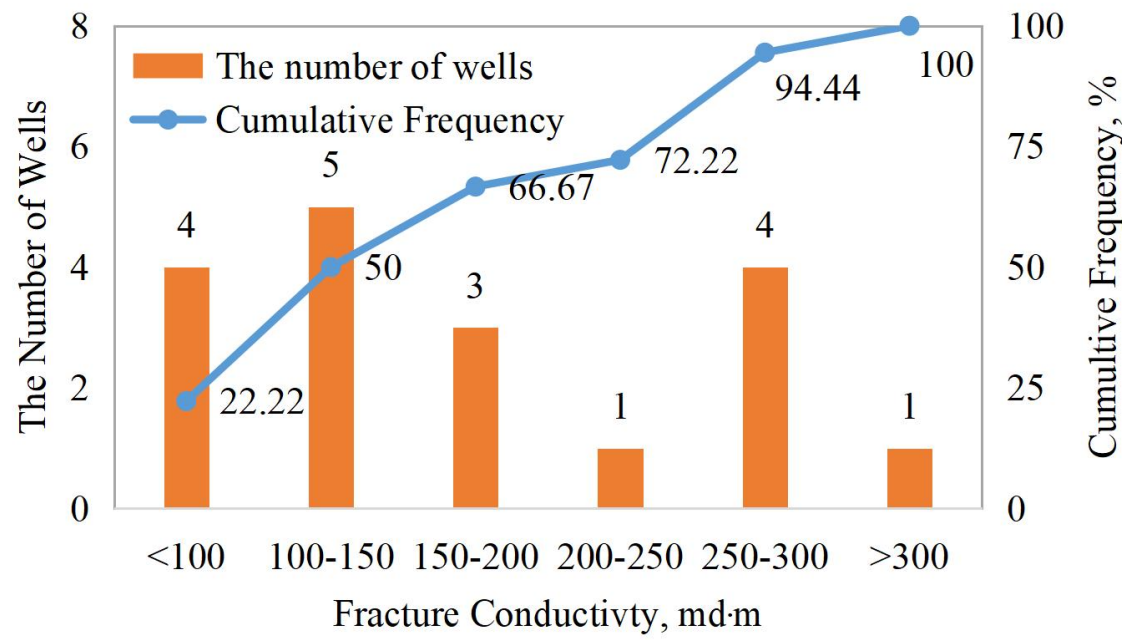

Figure 16-Cumulative frequency distribution of horizontal well fracture conductivity range.

\section{Conclusions}

Compared with the analytical well test, the numerical well test can obtain the reservoir and wellbore information more accurately, and the application effect of the numerical well test is better in the tight and strong heterogeneous sandstone gas field.

\section{Conflicts of Interest}

The author(s) declare that they have no conflicting interests.

\section{References}

Deng, H., Bao, X., Chen, Z., et al. 2011. Numerical Well Testing Using Unstructured PEBI Grids. Paper presented at SPE Middle East Unconventional Gas Conference and Exhibition, Muscat, Oman. 31 January-2 February. SPE-142258-MS.

Li, S. 2000. Gas Engineering. Beijing, China: Petroleum Industry Press.

Liu, N. 2008. Practical Modern Well Testing Interpretation Method. Beijing, China: Petroleum Industry Press.

Qi, E., Hong, H., Tian, W., et al. 2007. Application of Numerical Well Test Analysis in Complex Gas Wells. Natural Gas Industry 27(5): 97-99. 
Wang, B., Jia, Y., Li, Y. et al. 2013. A New Solution of Well Test Model for Multistage Fractured Wells. Acta Petrlolei Sinica 34(6): 1150-1156.

Wu, M., Yao, J., Jia, W., et al. 2010. Streamline Numerical Well-Testing Interpretation Model For Horizontal Wells And Its Application. Xinjiang Petroleum Geology 31(4):408-412.

Yang, L., Chang, Z., Zhu, Z., et al. 2010. Application of Numerical Well Test in Development of Kela 2 Gas Field. Natural Gas Geoscience 21(1):163-167.

Zheng, S. 2006. Fighting against Non-Unique Solution Problems in Heterogeneous Reservoir through Numerical Well Testing. Paper presented at SPE Asia Pacific Oil \& Gas Conference and Exhibition, Adelaide, Australia. 11-13 September. SPE-100951-MS.

Zhuang, H. 2004. Gas Reservoir Dynamic Description and Well Testing. Beijing, China: Petroleum Industry Press.

Yanyan Sun has worked as a reservoir engineer at Research Institution of Petroleum Exploration and Development, Changqing Oilfield, Petrochina, for the last 12 years. His research interests are in dynamic analysis for low permeability gas reservoir. He holds a Bachelor degree in resources exploration from Chengdu University of Technology.

Jiwu Fan is a senior reservoir engineer at Research Institution of Petroleum Exploration and Development, Changqing Oilfield, Petrochina. His research interests are in dynamic analysis for low permeability gas reservoir. He holds a Bachelor degree in Mathematics from Jilin University.

Zhenping $\mathbf{X u}$ is a reservoir engineer at Research Institution of Petroleum Exploration and Development, Changqing Oilfield, Petrochina, where she has worked for the last 7 years. Her research interests are in well testing for low permeability gas reservoir. She holds a master degree in field development from Southwest Petroleum University.

Zhichao $\mathbf{L i}$ is a reservoir engineer Research Institution of Petroleum Exploration and Development, Changqing Oilfield, Petrochina, where he has worked for the last 9 years. His research interests are in development geology for low permeability gas reservoir. He holds a Bachelor degree in resources exploration from Xi'an Shiyou University. 